\title{
Murine vocalizations: Experimental validation of a novel detector
}

\author{
REX L. CLARKE, ROBERT F. SMITH, DON R. JUSTESEN, and CHARLES L. SHERIDAN \\ U.S. Veterans Administration Medical Center, Kansas City, Missouri \\ and \\ William D. CUSHMAN \\ University of Maryland, Baltimore, Maryland
}

\begin{abstract}
A new device to detect vocalizations by mice or rats is described. Of modest cost and incorporating integrated circuits and controls that permit rapid setting of center frequency and sensitivity, the device is based on phase-locked tone decoding and can operate at sonic or ultrasonic frequencies. Circuit operation and schematics are provided, as are data from two studies of mice in which reliable discrimination of distress and submission calls from background noise was demonstrated.
\end{abstract}

Aggressive behavior by murine species is accompanied by vocalizations, some within and some beyond the range of human hearing (see, e.g., Morgret, 1972; Morgret \& Dengerink, 1972). Ultimately, independent visual observation by human observers must validate the occurrence of fighting, dominance, submission, and the like, but detection by electronic means of sonic signals that are associated with specific behaviors has obvious advantages: Labor costs are reduced, and monitoring of behavior may take place over long periods of time without human supervision. Existing electronic detectors are generally plagued by two problems (but see the elaborate, computerbased system of Paranjape, Secord, \& Voss, 1983): Discrimination between aggression calls and background noise is often faulty, and selectivity across the sonic spectrum is often poor, which results in inadequate differentiation of behavior-specific vocalizations. In this paper we describe a relatively inexpensive, prototypal apparatus with greater flexibility, selectivity, and noise-rejection capability than most of its predecessors.

All the simple squeal-squeak detectors described in the literature (Brain, Benton, Cole, \& Prowse, 1980); Davis, Perrot, \& Hubbard, 1972; Harrison \& Holman, 1978; Morgret \& Dengerink, 1972) have utilized some form of resistive-capacitive ( $\mathrm{RC}$ ) filter to discriminate rodent squeals from background noise. The RC filter circuit employed in Brain et al. (1980) and Harrison and Holman (1978) was the Twin-T filter. The difficulty with the Twin- $\mathrm{T}$ lies in its relative inflexibility; for example, six

R. L. Clarke, R. F. Smith, and D. R. Justesen are with Behavioral Radiology Research Laboratories, U.S. Veterans Administration Medical Center, Kansas City, MO 64128. They are also affiliated with the University of Kansas School of Medicine, Kansas City, KS 66103. C. L. Sheridan is now on the faculty of the University of Missouri at Kansas City, MO 64110. W. D. Cushman is with the Department of Psychology, University of Maryland, Baltimore, MD 21201. component values must be changed in precise mathematical ratio to shift the center frequency $\left(\mathrm{f}_{0}\right)$ while retaining good off-frequency rejection. The bandwidth (BW) of the Twin- $T$ is a function of how nearly these six components approximate the mathematical ideal. If the BW is too broad, the device is susceptible to spurious triggering. Furthermore, there is no simple method, without external circuitry, of altering delay-that is, the number of cycles at a frequency within the BW that are needed to trigger the device. This problem could be resolved by a strategy employed by Paranjape et al. (1983), who devised a wideband, digital, ultrasound recorder. However, the high cost of this device would make it beyond the reach of many investigators.

We have developed a squeal detector based on the phase-locked-loop (PLL) principle. This squeal detector may be adjusted over a considerable range of frequencies by a single control. Additional features of the PLL detector (based on the IC-567) include better rejection of out-of-band noise and directly adjustable BW, delay, and sensitivity (see Signetics Corporation, 1974). The PLL rodent-squeal detector evolved from the insight that the problem of detecting these vocalizations is analogous to that found in telephone systems that utilize touch-tone dialing: that is, tone decoding.

\section{CIRCUIT DESIGN AND OPERATION}

The circuit diagram of the squeal detector is shown in Figure 1. The two IC-567s are PLL tone decoders. Their function is to turn on their respective halves of the IC556 dual timer whenever a signal within the detection band is received from the amplifier. The $f_{0}$ of the IC-567s is compared with the input frequency to determine if there will be an output. This $f_{0}$ is adjustable (by the $10-k \Omega$ frequency-adjusting rheostat) from 1.8 to $11.0 \mathrm{kHz}$. This 


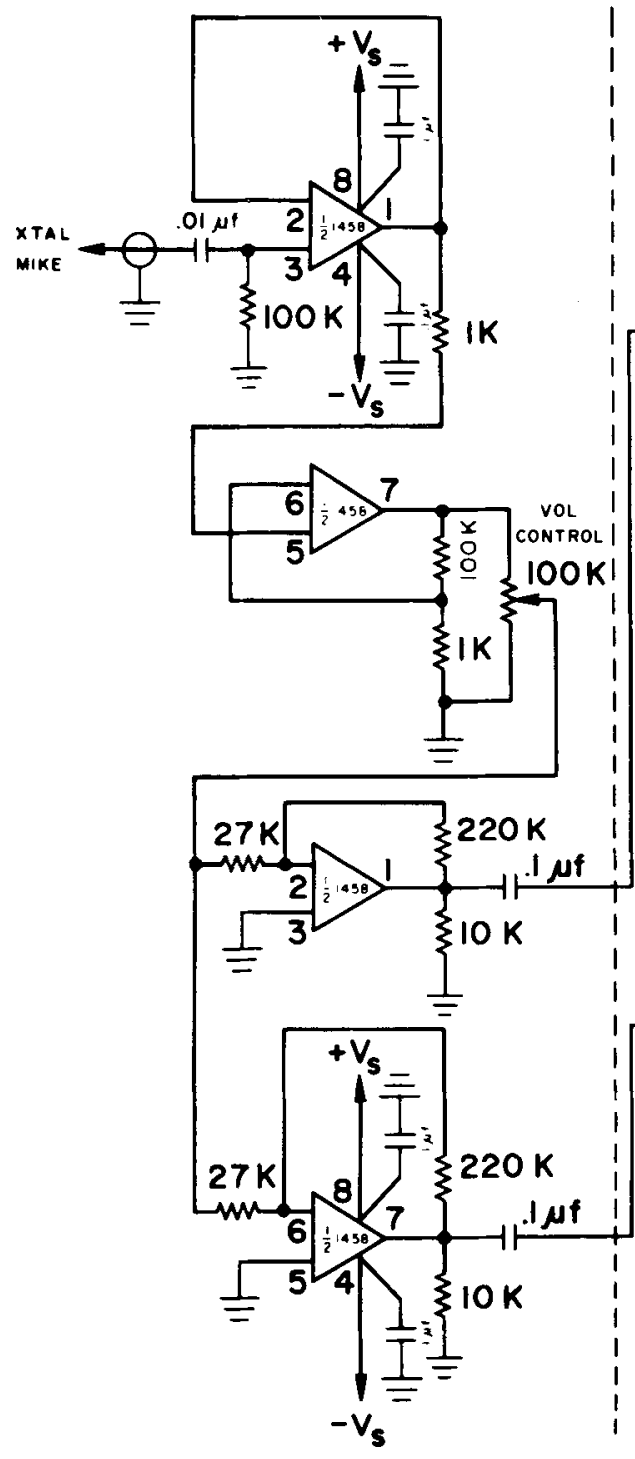

AMPLIFIER

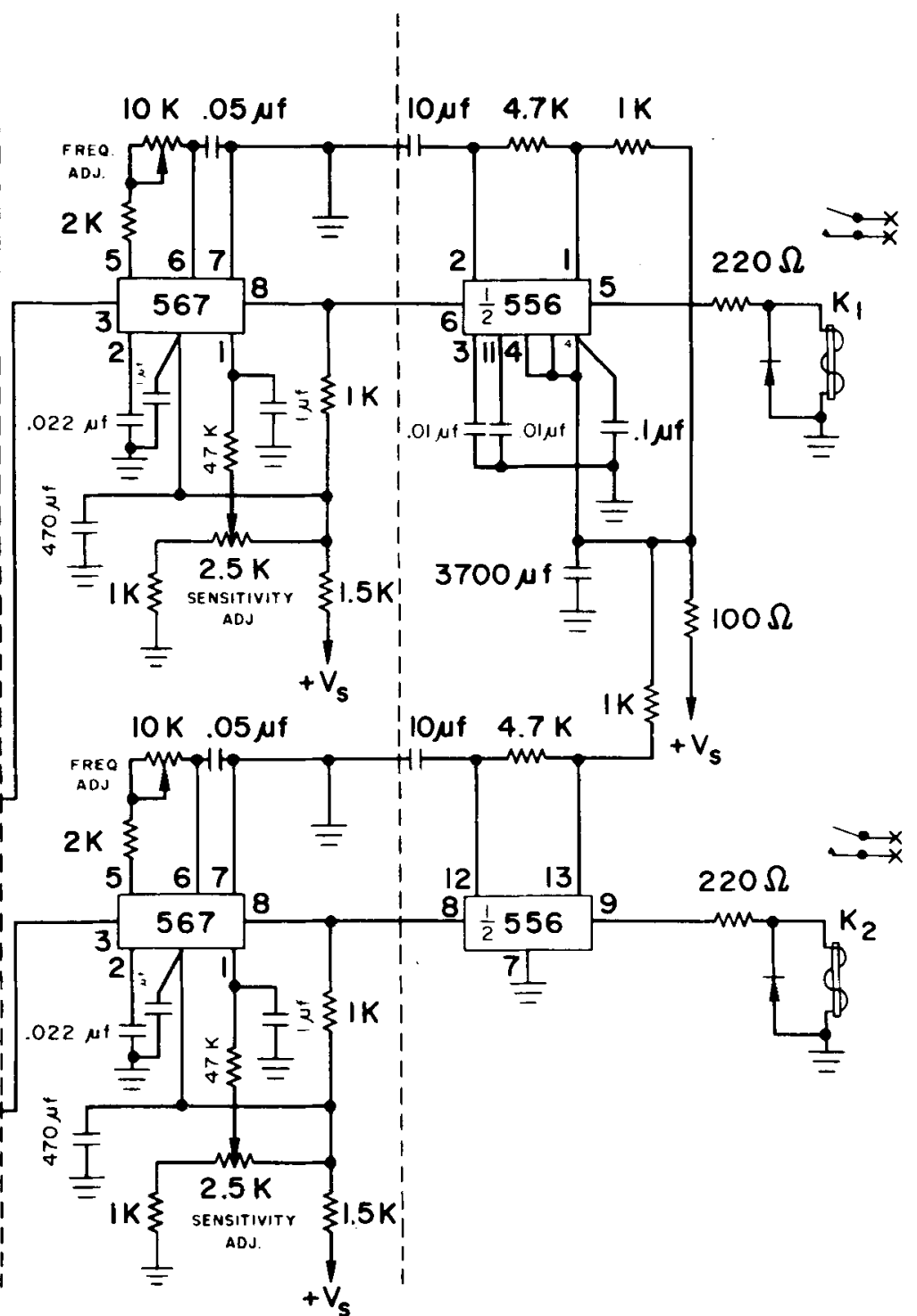

TONE DECODER
TIMER

Figure 1. Circuit diagram of a two-channel murine squeal detector. For maximal efriciency, the center frequencies of the two decoders should bracket the dominant frequency of the target vocalization. (All resistances are given in ohms.)

range should be more than adequate to optimize the detection of squeals from mice of any given strain.

The detection BW is that frequency range centered about $f_{0}$ within which an input signal above some threshold value will induce an output from the tone decoders. A BW from zero to about $14 \%$ of $f_{0}$ is achievable with the IC-567 (Signetics Corporation, 1974). The values of the external components shown in Figure 1 produce a BW near $12 \%$ of $f_{0}$, given a $V_{\text {in }} \leq 200 \mathrm{mV}$ rms.

All components were mounted on three phenolic PC boards $(5.4 \times 3.8 \mathrm{~cm})$ by standard point-to-point soldered connections. The entire circuit was mounted on stand-off insulators inside a louvered metal cabinet $(13.3 \times 24.1$ $\times 17.1 \mathrm{~cm}$ ) to provide a completely encompassing faraday shield. The current supply for the circuit (Figure 2) was placed inside the metal cabinet and was calibrated for -15 and $+15 \mathrm{~V}$ with respect to ground.

The IC-567s were calibrated by placing the squeal detector's crystal microphone (Realistic Model 33100) $12 \mathrm{~cm}$ from a speaker (Realistic 40-248)-the nominal mouse-to-microphone distance within the test cage. The speaker was connected to a Hewlett-Packard HP-204D audio oscillator and Heathkit IM-4110 frequency counter. The oscillator frequency was first set at $3.35 \mathrm{kHz}$, which approximates the dominant frequency of the squeals found during observed social aggression in the CD-1 mouse (Figure 3). The oscillator gain was calibrated to produce the same average reading on the VU meter of a Realistic SCT-2 cassette recorder that was produced by squealing mice at an equal distance when the same micro- 


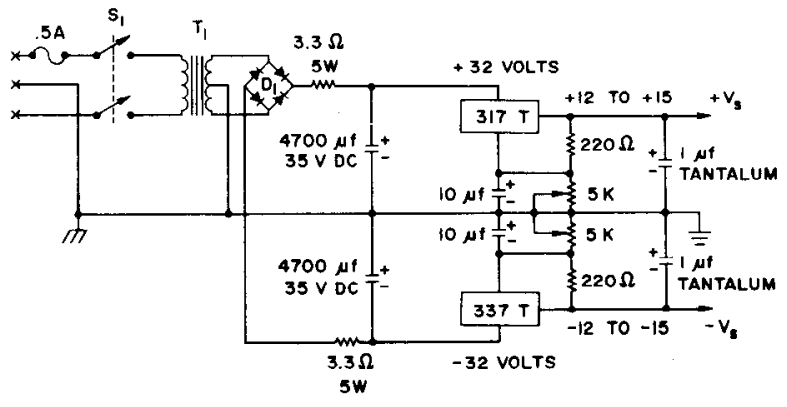

Figure 2. Circuit diagram of power supply. The power supply is a multipurpose laboratory instrument capable, with suitable heat sinking, of supplying current to $1.5 \mathrm{~A}$ at $0.3 \%$ load regulation $(0.01 \%$ line regulation).

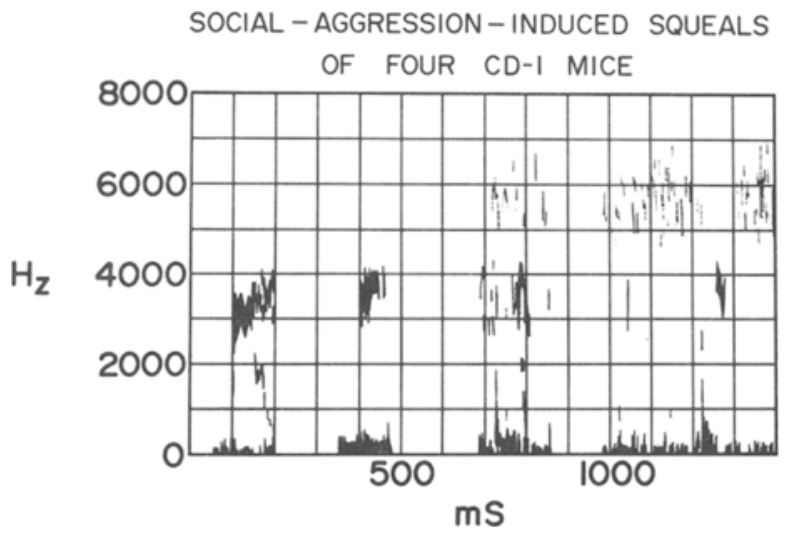

Figure 3. Sound spectrographs from tape recordings of CD-1 mice, which were made under conditions of visually verified social aggression.

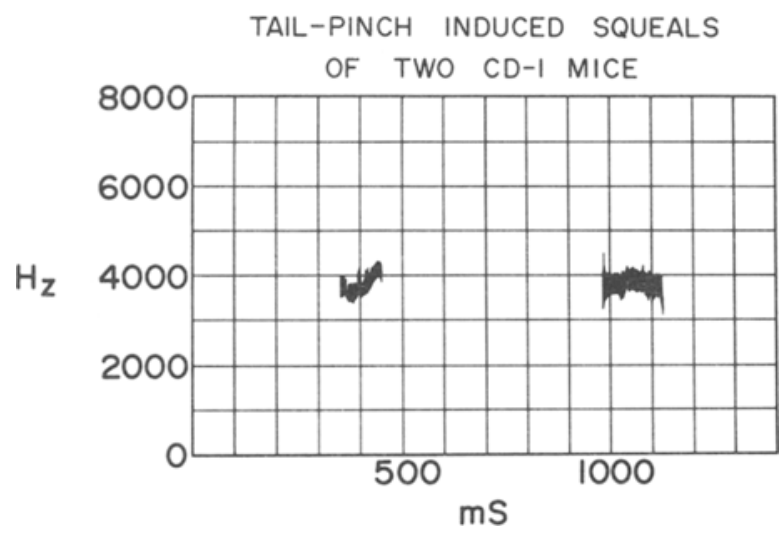

Figure 4. Sound spectrographs of tailpinch-elicited squeals of two CD-1 mice.

phone was used (Model 33100). The volume-control potentiometer in the amplifier section of the squeal detector was adjusted to provide an output of $200 \mathrm{mV}$ at terminal 3 of the IC-567s, as measured by a Heathkit IM102 digital multimeter. The center frequency $\left(f_{0}\right)$ of the first PLL was set via the frequency-adjust rheostat to correspond to the HP-204 frequency (i.e., $3.35 \mathrm{kHz}$ ).
The $\mathrm{f}_{0}$ of the second tone decoder was set at $3.85 \mathrm{kHz}$ via the HP-204 oscillator and the IM-4110 frequency counter. This PLL was used to detect signals of the type produced by tailpinch (Figure 4).

The final adjustments to the IC-567s involved setting the sensitivity potentiometers while mouse squeals of the appropriate type were placed on the SCT-2 cassette recorder. These recordings were subjected to spectrographic analysis (Voice Identification, Inc., spectrograph, 700 Series, International Radio and Electronics Corporation) in production of data for Figures 3 and 4.

\section{OBSERVATIONAL STUDY 1}

\section{Method}

Fifty male albino mice of the CD-1 strain were housed in groups of five in standard $26 \times 15 \times 12.5 \mathrm{~cm}$ mouse cages in the Animal Research Facility of the Veterans Administration Medical Center, Kansas City, Missouri. Purina Lab Chow and water were continuously available, including during periods when behavioral observations were made. During numerous trials, we verified that the noise made by contact of these pellets with cage walls and floor or by movements of the mice would not actuate either PLL of the squeal detector when they were properly adjusted as to $f_{0}$ and sensitivity. The temperature of the rooms was maintained at $24 \pm 1.5^{\circ} \mathrm{C}$, and a 12:12 light:dark schedule (lights off at $1200 \mathrm{~h}$ ) was employed

All experiments were conducted in an anechoic chamber $(0.9 \times 1.4 \mathrm{~m})$ under red light beginning at $1200 \mathrm{~h}$ each day and extending to $1200 \mathrm{~h}$ of the following day. The test cage itself was $20.8 \times 14.6 \times 11.5 \mathrm{~cm}$ and was composed of 10 -mm-thick Plexiglas; a perforated lid was constructed of the same material. On the cage lid was an all-glass water bottle and a crystal microphone in a foam-rubber socket. The microphone was attached via coaxial cable to the PLL squeal detector, which was located outside the anechoic chamber. The floor of the test cage was covered with $\sim 28 \mathrm{~g}$ of wood shavings. The test cage rested on top of the remote antenna of a LKB Animex activity monitor (Type DSE), which was also located outside the anechoic chamber.

The CD-1 mice were received as a group at 9 weeks of age and were assigned randomly to one of 10 cages (five mice per cage). Previous pilot experiments by the authors have confirmed that crowding produces intraspecific aggression in the CD-1 mouse, as it does in animals of other murine strains and species (Calhoun, 1948; Crew \& Mirskaia, 1931). After 3 weeks, one or more animals in each cage showed clear signs (wounds and defurred spots) of being the target for aggression by more dominant mice (Bertilson, Mead, Morgret, \& Dengerink, 1977; Long, 1972; Scott, 1966; Scott \& Fredericson, 1951).

At this time, the behavioral measures commenced. A group of mice was selected at random, and all five members of a single cage were picked up individually by their tails and placed in a clean test cage with fresh wood shavings and $10 \mathrm{~g}$ of Purina Lab Chow. The test cage was then placed on top of the remote antenna of the LKB activity monitor, the microphone and water bottle were installed, and the anechoic chamber was closed for $24 \mathrm{~h}$. Fresh air and masking noise inside the chamber were provided by a blower attached to the chamber's outer wall. The rate of air flow at the blower's input baffle was $1 \mathrm{~m} / \mathrm{sec}$ as measured by a Kurz Model 441M air-velocity meter.

The outputs from the LKB monitor and the squeal detector were directed through stepping relays (controlled by a 1-h clock) to banks of counters. These counters provided frequency counts of activity and squeals in $1-\mathrm{h}$ blocks across the $24 \mathrm{~h}$.

\section{Results}

We found that mice of the CD-1 strain emit a few spontaneous squeals of the type seen in the sound spectrograph in Figure 4. These squeals are not prompted by experimenter-induced physical annoyance (tailpinch). The animals appear to emit these squeals under conditions of 
stress or fright not usually precipitated by a conspecific. In a pilot experiment, even isolated mice were observed to emit a few of these calls during the first few hours in a new cage. After a survey of the conditions that elicited the vocalizations shown in Figure 4 (handling, new or unfamiliar cage, tailpinch delivered by the experimenter), we settled on the term "fright call" as best fitting the circumstances.

Because squeals of the form shown in Figure 3 were emitted by the targets of aggression by a conspecific, we dubbed these "submission calls," as have other researchers using different strains of mice (Brain et al., 1980).

When viewed against the background of the highly frequent emission of the submission call during a 24-h period by a group of CD-1 mice, the number of fright calls is insignificant $-a$ fraction of one percent. These fright calls are attributable either to stress induced previously by handling or to the unfamiliar environment of the test cage.

\section{OBSERVATIONAL STUDY 2}

\section{Method}

The same 50 CD-1 mice were used that had been used in the previous study. Conditions were identical, except that the $f_{0} s$ and sensitivity settings of the squeal detector were changed.

Because of the small number of fright calls overall, it was evident that a more efficient device would result if we simply ignored the fright calls and accepted a few spurious submission squeals during the first few hours in a strange cage. Accordingly, the $f_{0} s$ were reset at 3.4 and $3.9 \mathrm{kHz}$, respectively, and sensitivity was maintained at a high level. The output relays were paralleled to form an OR circuit. When a standard tape recording of CD-1 mice was made during observer-verified social aggression and was played to the detector's microphone, a total of $93 \%$ of the mean number of submission squeals (122) was recorded on the mechanical counter (squeals counted by three independent observers yielded a $\mathrm{z}$-averaged $\mathrm{r}$ of .86 ).

\section{Results}

The squeals emitted during social aggression are much more complex than the rather narrow-banded squeals induced by tailpinch. In pattern, the vocalizations that occur during aggression resemble a human fricative speech sound that contains dominant frequencies imbedded in wide-spectrum noise (Ghiselli \& LaRiviere, 1977). The reliable detection of these complex vocalizations is facilitated by the dual-channel PLL. Since maximal BW is limited in the IC-567, a single-channel detector could not span all the dominant frequencies found in many of these squeals. A measure of the success of the PLL detector in detection of broadband signals may be seen in Figure 5, which reveals a high correlation between activity and occurrence of squeals.

\section{GENERAL DISCUSSION}

The PLL squeal detector appears to solve many of the problems that have plagued its predecessorshypersensitivity to out-of-band noise, complexity, excessive bandwidth, and lack of ready control of center frequency. Its capabilities, however, are by no means con-

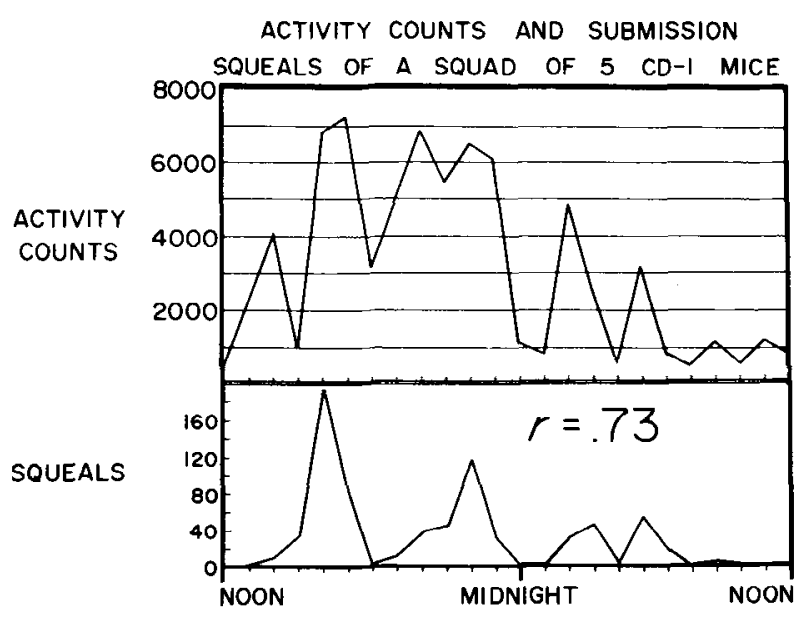

Figure 5. Concomitant counts of activity and social squeals of a group of five male CD-1 mice. The mice had been acclimated for 3 weeks to a circadian schedule in which they were in darkness from noon until midnight; a visible light was then illuminated from midnight until noon of the following day. During the measures reported here, they were continuously exposed to (nonvisible) red light. The Pearson product-moment correlation between hourly-averaged counts is $.73(\mathrm{df}=22, \mathrm{p}<.001)$.

fined to sonic frequencies. The IC-567 is capable of operating with an $f_{0}$ anywhere between 0.01 and $500 \mathrm{kHz}$ (Signetics Corporation, 1974). Only changes in the microphone, amplifier, and the tuning resistor-capacitor of the IC-567 would be necessary to convert the circuit in Figure 1 to an ultrasonic detector (Pye \& Flinn, 1964).

A less obvious use of the tone decoder is as an activity detector. If, for example, a few connecting capacitors were increased in value in the amplifier, and if the $\mathrm{f}_{0}$ were set at about $100 \mathrm{~Hz}$, a very serviceable and inexpensive activity detector would be created if the subjects were placed on an inherently noisy substrate, such as Sanicel litter.

Finally, we would like to comment on the finding that the murine squeal, at least in mice of the CD-1 strain, is not so simple a vocalization as has been surmised. It should not be surprising if vocalizations conveyed information about an animal's emotional state, even in Mus musculus; Noirot (1974) found, for example, that ultrasounds emitted by chilled, inaccessible pups induced virgin female mice to build larger, better insulated nests.

\section{REFERENCES}

Bertilson, H. S., Mead, J. D., Morgret, M. K., \& Dengerink, H. A. (1977). Measurement of mouse squeals for 23 hours as evidence of long-term effects of alcohol on aggression in pairs of mice. Psychology Reports, 41, 247-250.

Brain, P. F., Benton, D., Cole, C., \& Prowse, B. (1980). A device for recording submission vocalizations of laboratory mice. Physiology \& Behavior, 24, 1003-1006.

Calhoun, J. B. (1948). Mortality and movement of brown rats (Rattus norvegicus) in artificially supersaturated populations. Journal of Wildlife Management, 12, 167-172.

Crew, F. A. E., Mirskaia, L. (1931). The effects of density on an adult mouse population. Biologia generalis, 7, 239-250. 
Davis, H., Perrot, D., \& Hubbard, J. (1972). An automated apparatus for recording shock elicited vocalization in the rat. Physiological Record, 22, 71-74.

GHISELLI, W. B., \& LARIVIERE, C. (1977). Characteristics of ultrasonic vocalizations emitted by rats during shock-elicited aggression. Animal Learning \& Behavior, 5, 199-202.

Harrison, G. E., Holman, S. D. (1978). A device to enable the automatic recording of rodent ultrasonic vocalization. Behavior Research Methods \& Instrumentation, 10, 689-692.

LoNG, S. Y., (1972). Hair-nibbling and whisker-trimming as indicators of social hierarchy in mice. Animal Behaviour, 20, 10-12.

MORGRET, M. K. (1972). An apparatus for detection and counting of mouse squeals. Behavior Research Methods \& Instrumentation, 4, 21-23.

Morgret, M. K., \& Dengerink, H. A. (1972). The squeal as an indicator of aggression in mice. Behavior Research Methods \& Instrumentation, 4, 138-140.
Norrot, E. (1974). Nest-building by the virgin female mouse exposed to ultrasound from inaccessible pups. Animal Behaviour, 22, 410-420.

Paranjape, R. B., Secord, D. C., \& Voss, W. A. G. (1983). Instrumentation and techniques-A digital ultrasound recorder. Behavior Research Methods \& Instrumentation, 15, 497-502.

PyE, J. D., \& FLINN, M. (1964). Equipment for detecting animal ultrasound. Ultrasonics, 2, 23-28.

Scott, J. P. (1966). Agonistic behavior of mice and rats: A review. American Zoologist, 6, 683-701.

SCOTT, J. P., \& Fredericson, E. (1951). The causes of fighting in mice and rats. Physiological Zoology, 4, 273-309.

Signetics Corporation. (1974). Signetics data book (pp. 96-105). Sunnyvale, CA: Author.

(Manuscript received January 4, 1983; revision accepted for publication October 3,1984 .) 